\title{
Early fundoplication is associated with slower decline in lung function after lung transplantation in patients with gastroesophageal reflux disease
}

Sreeja Biswas Roy, MBBS, ${ }^{\mathrm{a}}$ Shaimaa Elnahas, MD ${ }^{\mathrm{a}}$ Rosemarie Serrone, MD, ${ }^{\mathrm{b}}$ Cassandra Haworth, BS, Michael T. Olson, ${ }^{\mathrm{d}}$ Paul Kang, MS, MPH, ${ }^{\mathrm{e}}$ Michael A. Smith, MD, ${ }^{\mathrm{a}}$ Ross M. Bremner, MD, PhD, ${ }^{\mathrm{a}}$ and Jasmine L. Huang, MD

\section{ABSTRACT}

Objectives: Gastroesophageal reflux disease (GERD) is prevalent after lung transplantation. Fundoplication slows lung function decline in patients with GERD, but the optimal timing of fundoplication is unknown.

Methods: We retrospectively reviewed patients who underwent fundoplication after lung transplantion at our center from April 2007 to July 2014. Patients were divided into 2 groups: early fundoplication $(<6$ months after lung transplantation) and late fundoplication ( $\geq 6$ months after lung transplantation). Annual decline in percent predicted forced expiratory volume in 1 second $\left(\mathrm{FEV}_{1}\right)$ was analyzed.

Results: Of the 251 patients who underwent lung transplantation during the study period with available $\mathrm{pH}$ data, $86(34.3 \%)$ underwent post-transplantation fundoplication for GERD. Thirty of $86(34.9 \%)$ had early fundoplication and 56 of $86(65.1 \%)$ had late fundoplication. Median time from lung transplantation to fundoplication was 4.6 months (interquartile range, 2.0-5.2) and 13.8 months (interquartile range, 9.0-16.1) for the early and late groups, respectively. The median DeMeester score was comparable between groups. One-, 3-, and 5-year actuarial survival rates in the early group were $90 \%, 70 \%$, and $70 \%$, respectively; in the late group, these rates were $91 \%, 66 \%$, and $66 \%$ (log rank $P=.60$ ). Three- and 5-year percent predicted $\mathrm{FEV}_{1}$ was lower in the late group by $8.9 \%$ ( $95 \%$ confidence interval, -30.2 to $12.38 ; P=.46)$ and $40.7 \%$ (95\% confidence interval, -73.66 to $-7.69 ; P=.019)$. A linear mixed model showed a $5.7 \%$ lower percent predicted $\mathrm{FEV}_{1}$ over time in the late fundoplication group $(P<.001)$.

Conclusions: In this study, patients with early fundoplication had a higher $\mathrm{FEV}_{1}$ 5 years after lung transplantation. Early fundoplication might protect against GERD-induced lung damage in lung transplant recipients with GERD. (J Thorac Cardiovasc Surg 2018;155:2762-71)

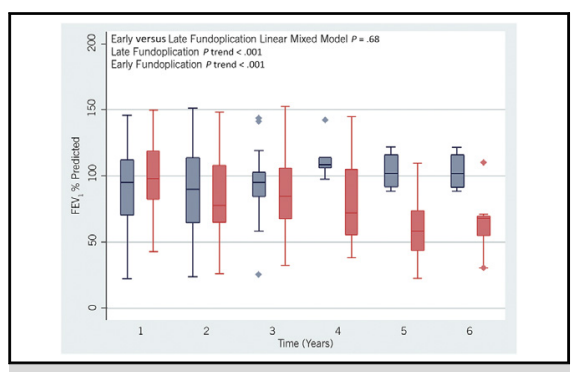

Significantly lower $\mathrm{FEV}_{1}$ over time in late versus early fundoplication group $(P=.019)$.

\section{Central Message}

Early fundoplication (ie, within 6 months of transplantation) might protect against GERD-induced lung damage in lung transplant recipients with GERD

\section{Perspective}

GERD is prevalent in the lung transplantation population. Early surgical correction of GERD (ie, within 6 months of transplantation) might slow the rate of lung function decline after transplantation by protecting against reflux-induced lung damage. Lung transplant recipients might benefit from routine surveillance protocols for GERD early in the post-transplantation period.

See Editorial Commentary page 2772.

See Editorial page 2760.
From the a Norton Thoracic Institute, 'Department of General Surgery, St. Joseph's Hospital and Medical Center, Phoenix, Ariz; ${ }^{\mathrm{c}}$ A.T. Still University School of Osteopathic Medicine, Mesa, Ariz; ${ }^{\mathrm{d}}$ Grand Canyon University, Phoenix, Ariz; and ${ }^{\mathrm{e}}$ University of Arizona College of Public Health, Phoenix, Ariz.

Read at the 43rd Annual Meeting of The Western Thoracic Surgical Association, Colorado Springs, Colorado, June 21-24, 2017.

Received for publication June 21, 2017; revisions received Jan 26, 2018; accepted for publication Feb 5, 2018; available ahead of print March 20, 2018.

Address for reprints: Jasmine L. Huang, MD, Norton Thoracic Institute, St. Joseph's Hospital and Medical Center, 500 W Thomas Rd, Ste 500, Phoenix, AZ 85013 (E-mail: Jasmine.Huang@dignityhealth.org).

0022-5223/\$36.00

Copyright (c) 2018 by The American Association for Thoracic Surgery

https://doi.org/10.1016/j.jtcvs.2018.02.009
Lung transplantation is increasingly being offered as treatment for patients with end-stage lung disease. However, chronic lung allograft dysfunction (CLAD) remains the biggest limiting factor to prolonged

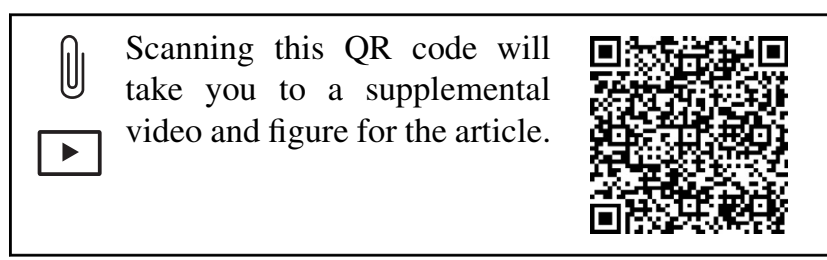




\author{
Abbreviations and Acronyms \\ BOS = bronchiolitis obliterans syndrome \\ $\mathrm{CI}=$ confidence interval \\ CLAD $=$ chronic lung allograft dysfunction \\ $\mathrm{FEV}_{1}=$ forced expiratory volume in 1 second \\ GERD $=$ gastroesophageal reflux disease \\ $\mathrm{IQR}=$ interquartile range \\ LAS = lung allocation score \\ LES = lower esophageal sphincter \\ LESP $=$ lower esophageal sphincter resting \\ pressure \\ N/A $=$ not applicable \\ SAP $=$ symptom association probability
}

post-transplantation survival. A common clinical equivalent of CLAD is bronchiolitis obliterans syndrome (BOS), which is defined as an obstructive defect in ventilation and a persistent decline in forced expiratory volume in $1 \mathrm{sec}-$ ond $\left(\mathrm{FEV}_{1}\right) \leq 80 \%$ below post-transplantation baseline. ${ }^{1}$ Several immune and nonimmune factors have been implicated in the pathogenesis of BOS.,3 Gastroesophageal reflux disease (GERD) has been suggested as an important nonimmune contributor in BOS development (Video 1). The direct injury that results from prolonged exposure to acidic refluxate, which is laden with gastrointestinal digestive enzymes, has been proposed to intensify the immune pathway of BOS pathogenesis. ${ }^{4}$

GERD affects up to $20 \%$ of the general population, increasing by $4 \%$ to $5 \%$ per year over the past 2 decades. The prevalence of GERD in patients with end-stage lung disease who undergo lung transplantation is much higher - up to $63 \% .^{5}$ The incidence of GERD increases even more after transplantation because of vagal denervation, delayed gastric emptying, and immunosuppressive medications. Although proton pump inhibitors decrease the acidity of the refluxate, they have no effect on gastroesophageal motility, mucociliary function, or cough reflex, which are the mainstay mechanisms behind the development of GERD after lung transplantation.

Fundoplication has been the gold standard of GERD treatment after lung transplantation. Although a causal relationship has yet to be established between GERD and BOS, fundoplication has been shown to reduce the proinflammatory environment in lung parenchyma, ${ }^{6}$ and has also been shown to decrease biomarkers for aspiration in lung transplant recipients. ${ }^{7}$ Few studies have examined the effect of the timing of antireflux surgery on the progress of BOS. ${ }^{8,9}$ Early fundoplication (ie, within 6 months of transplantation) has resulted in improved rates of freedom from BOS. ${ }^{8,9}$ In the current study, we examined our singlecenter experience with prevalence of GERD and outcomes of fundoplication in lung transplant recipients, with a special

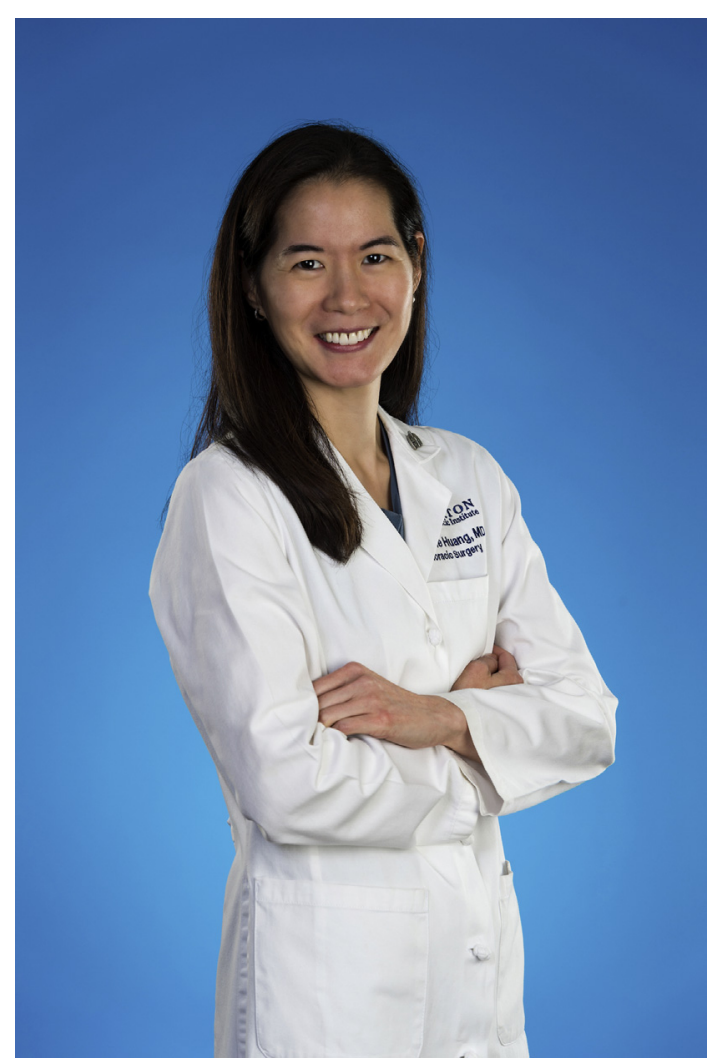

VIDEO 1. Senior author Jasmine Huang describes the findings in this study, namely, that early fundoplication (ie, within 6 months of transplantation) might protect against GERD-induced lung damage in lung transplant recipients with GERD. Video available at: http://www. jtcvsonline.org/article/S0022-5223(18)30357-X/fulltext.

focus on the timing of fundoplication post-transplantation. We also reviewed our current practice of GERD surveillance in this patient population. Our goal was to compare the effects of early ( $<6$ months) versus late ( $\geq 6$ months) fundoplication on pulmonary function as well as survival in lung transplant recipients. We hypothesized that early fundoplication would be associated with stabilization of lung function and, subsequently, increased survival and freedom from BOS after lung transplantation.

\section{METHODS}

After approval from the Institutional Review Board at St. Joseph's Hospital and Medical Center (Institutional Review Board approval number: PHXA-17-0009-71-18, October 19, 2016), we retrospectively reviewed the charts of patients who underwent fundoplication after lung transplantation at Norton Thoracic Institute between April 2007 and July 2014. Patients were divided into 1 of 2 groups: early fundoplication (ie, within 6 months of lung transplantation) and late fundoplication (ie, 6 months or more after lung transplantation). The 2 groups were compared for demographic characteristics, lung allocation score (LAS), comorbidities, type of fundoplication, and postoperative outcomes. Pretransplantation GERD workup included high-resolution manometry, 24-hour $\mathrm{pH}$ 
monitoring, esophagogastroduodenoscopy, and a gastric emptying study. In patients who were bedbound and who underwent lung transplantation on an urgent basis, the GERD workup was completed at the earliest opportunity post-transplantation. Post-transplantation GERD surveillance was initiated 3 months after transplantation; surveillance endoscopy was also performed at this time to look for stigmata of GERD.

\section{Immunosuppression}

The immunosuppressive regimen was uniform across the study period. Induction therapy included high-dose glucocorticoids (methylprednisolone) before perfusion of the lung allografts, with interleukin-2 receptor antibody (basiliximab) or anti CD-20 monoclonal antibody (rituximab), with or without antithymocyte globulin. Maintenance therapy consisted of a steroid, mycophenolate acid, and tacrolimus. Episodes of acute cellular rejection were treated with pulsed steroids, followed by steroid taper.

\section{Surveillance}

Clinic-based spirometry was used to record $\mathrm{FEV}_{1}$ measurements to monitor lung function after transplantation. Pulmonary function was tested every 2 to 3 weeks in the first 6 months, every 4 weeks in the next 6 months to 2 years, and every 3 to 6 months after the 2-year mark. Additional measurements were obtained during sick visits or upon suspicion of clinical worsening.

\section{pH Study}

GERD was diagnosed on the basis of ambulatory 24-hour pH monitoring, which was carried out 10 days after antireflux medications were withheld. Esophageal $\mathrm{pH}$ monitoring was performed using a catheter-based dual electrode probe (ComforTEC; Sandhill Scientific, Milwaukee, Wis). DeMeester score was calculated using the standard variables. $^{10}$ Symptom-reflux correlation was done using symptom association probability and symptom index scores. Normal values for acid contact times in the distal probe are: total $>4.2 \%$, upright $<6.3 \%$, and supine $<1.2 \%$. All studies were interpreted after clinical correlation by a thoracic surgeon. Because of the implications of proximal GERD on allograft function, our institutional protocol has evolved to incorporate routine GERD surveillance 3 months after transplantation.

\section{Fundoplication}

Patient selection for fundoplication was on the basis of diagnosis of persistent GERD in a 24-hour $\mathrm{pH}$ monitoring study with or without decline in lung function, or symptomatic GERD with a positive 24-hour $\mathrm{pH}$ monitoring study in the post-transplantation period. Laparoscopic reduction, repair of hiatal hernia, and fundoplication were performed in standard fashion. Wrap type (ie, $270^{\circ}$ or $360^{\circ}$ ) was selected based on the results of esophageal motility studies. After adequate esophageal mobilization of approximately 4 to $5 \mathrm{~cm}$ of intra-abdominal length, the hiatus was closed posteriorly with interrupted polyethylene sutures and reinforced with onlay biodegradable mesh as needed.

\section{Acute Rejection and BOS}

Acute rejection was graded on the basis of pathologic examination of transbronchial biopsy specimens obtained from surveillance bronchoscopies post-transplantation using standard criteria. ${ }^{11}$ Criteria set forth by the International Society for Heart and Lung Transplantation ${ }^{1}$ were used to diagnose the onset of BOS; more specifically, BOS was defined as a persistent decline of $20 \%$ or greater in $\mathrm{FEV}_{1}$ in the absence of confounding factors. No distinction was made in BOS severity, or in the presence or absence of restrictive allograft syndrome.

\section{Statistical Analysis}

Continuous variables were reported using median and interquartile range (IQR); categorical variables were reported as frequencies. The
Wilcoxon rank sum and Fisher exact tests were used for continuous and categorical variables, respectively. Freedom from BOS was determined using the Kaplan-Meier method. Actuarial survival at 1, 3, and 5 years was also estimated using the Kaplan-Meier method followed by the $\log$ rank test to ascertain any difference in probabilities. Survival in the study groups was further compared with 2 control groups: patients without evidence of GERD on $\mathrm{pH}$ monitoring, and patients with evidence of GERD who were managed medically. A linear mixed model was used to analyze decline in percent predicted $\mathrm{FEV}_{1}$ over time after lung transplantation. The Wilcoxon rank sum was implemented to ascertain any difference in $\mathrm{FEV}_{1} \%$ predicted at each time point. The Bonferroni correction was used to adjust for multiple comparisons. A $P$ value of $<.05$ was considered significant. All analyses were performed using Stata 2015 software, release 14 (StataCorp LP, College Station, Tex).

\section{RESULTS}

In total, 273 lung transplantations were performed at Norton Thoracic Institute between April 2007 and July 2014. Of these, $\mathrm{pH}$ data were available for 251 patients; 86 of 251 patients $(34.3 \%)$ underwent post-transplantation fundoplication for GERD during the study period. Thirty of these patients $(34.9 \%)$ underwent early fundoplication; 56 patients $(65.1 \%)$ underwent late fundoplication. Table 1 shows a summary of patient characteristics of the 2 groups. The 2 groups were comparable in terms of age and sex, but patients in the early group had higher median LASs and lower body mass indices. The median time from lung transplantation to fundoplication was 4.6 months (IQR, 2.0-5.2) and 13.8 months (IQR, 9.0-16.1) for the early and late groups, respectively. A greater proportion of patients in the early group had restrictive lung disease before transplantation. The 2 groups were comparable in terms of type of fundoplication (ie, Nissen wrap vs Toupet wrap). Patient outcomes are described in Table 2. The hospital length of stay for the procedure was a median of 2 days in both groups. There was no in-hospital or 30-day mortality in either group. The failure rate for fundoplication was $5.8 \%$, with 5 patients requiring redo surgery for recurrent symptoms or for wrap-related complications. Another 5 patients required endoscopic dilation or pyloric injection of botulinum toxin for persistent postoperative gastroparesis.

\section{pH Studies}

Table 3 lists the results of the 24-hour $\mathrm{pH}$ monitoring study recorded at the time of evaluation for lung transplantation. The 2 groups were comparable in all pretransplantation and prefundoplication $\mathrm{pH}$ metrics and DeMeester scores; however, some differences were observed in manometric measurements and endoscopic findings prefundoplication (Table 4). A greater proportion of patients in the late group had evidence of reflux esophagitis ( $61 \%$ vs $40 \%$ ) on esophagogastroduodenoscopy, indicating prolonged acid reflux; this difference was not statistically significant. On high-resolution manometry, the total lower esophageal sphincter length was shorter in the early group. Median acid exposure time in 
TABLE 1. Baseline characteristics of the fundoplication groups

\begin{tabular}{|c|c|c|c|c|}
\hline Variable & $\begin{array}{l}\text { Overall } \\
(n=86)\end{array}$ & $\begin{array}{l}\text { Early fundoplication } \\
\qquad(\mathbf{n}=\mathbf{3 0})\end{array}$ & $\begin{array}{l}\text { Late fundoplication } \\
\qquad(\mathrm{n}=\mathbf{5 6})\end{array}$ & $\boldsymbol{P}^{*}$ \\
\hline Median age at transplantation, $\mathrm{y}$ & $62.5(54.0-66.0)$ & $63.0(56.0-67.0)$ & $62.0(53.5-66.0)$ & .86 \\
\hline Male sex, n (\%) & $47(54.7)$ & $15(50.0)$ & $35(62.5)$ & .52 \\
\hline Median LAS at transplantation & $34.7(32.4-41.6)$ & $38.5(32.9-52.3)$ & $33.7(32.0-38.5)$ & .004 \\
\hline Median body mass index & $25.4(22.6-28.7)$ & $23.9(20.6-26.3)$ & $26.1(23.6-29.3)$ & .002 \\
\hline Diabetes mellitus before transplantation, $\mathrm{n}(\%)$ & $56(65.9)$ & $22(73.3)$ & $34(61.8)$ & .28 \\
\hline Bilateral lung transplantation, $\mathrm{n}(\%)$ & $86(100.0)$ & $30(100.0)$ & $56(100.0)$ & N/A \\
\hline $\begin{array}{l}\text { Underlying pulmonary diagnosis, n (\%) } \\
\text { Obstructive lung disease } \\
\text { Restrictive lung disease } \\
\text { Cystic fibrosis } \\
\text { Retransplantation } \\
\text { Other }\end{array}$ & $\begin{array}{c}53(61.6) \\
23(26.7) \\
7(8.1) \\
1(1.2) \\
2(2.3)\end{array}$ & $\begin{array}{c}13(43.3) \\
12(40.0) \\
3(10.0) \\
0(0.0) \\
2(6.7)\end{array}$ & $\begin{array}{c}40(71.4) \\
11(19.6) \\
4(7.1) \\
1(1.8) \\
0(0.0)\end{array}$ & .02 \\
\hline Median KPS at transplantation & $70(60-70)$ & $60(50-70)$ & $70(60-70)$ & .04 \\
\hline Median serum creatinine, $\mathrm{mg} / \mathrm{dL}$ & $1.1(0.84-1.3)$ & $1.0(0.80-1.2)$ & $1.1(0.89-1.3)$ & .12 \\
\hline Positive smoking history before transplantation, $\mathrm{n}(\%)$ & $59(70.2)$ & $20(68.9)$ & $39(70.9)$ & .85 \\
\hline $\begin{array}{l}\text { Type of fundoplication, } \mathrm{n}(\%) \dagger \\
\text { Toupet } \\
\text { Nissen } \\
\text { Dor }\end{array}$ & $\begin{array}{c}37(43.5) \\
47(55.3) \\
1(1.2)\end{array}$ & $\begin{array}{c}14(46.7) \\
15(50.0) \\
1(3.3)\end{array}$ & $\begin{array}{c}23(41.8) \\
32(58.2) \\
0(0.0)\end{array}$ & .19 \\
\hline Median time from lung transplantation to hernia repair, mo & $8.7(5.0-15.2)$ & $4.6(2.0-5.2)$ & $13.8(9.0-16.1)$ & $<.001$ \\
\hline
\end{tabular}

All values expressed as median (interquartile range), unless indicated otherwise. LAS, Lung allocation score; N/A, not applicable; KPS, Karnofsky performance score. *Calculated using Wilcoxon rank sum for continuous variables and Fisher exact for categorical variables. $†$ Calculated for 85 patients.

the distal $\mathrm{pH}$ channel increased from 99.5 minutes late group. Similarly, the median DeMeester pretransplantation to 144.9 minutes prefundoplication in the score increased from 31.7 pretransplantation to 46.8 early group, and from 58.6 minutes to 147 minutes in the prefundoplication in the early group and 19.3 to 49.7 in the

TABLE 2. Outcomes of post-transplantation fundoplication procedures

\begin{tabular}{|c|c|c|c|c|}
\hline Variable & Overall $(\mathbf{n}=86)$ & Early fundoplication $(n=30)$ & Late fundoplication $(n=56)$ & $P^{*}$ \\
\hline Median LOS after fundoplication, $\mathrm{d}$ & $2(2-3)$ & $2(2-4)$ & $2(1-3)$ & .13 \\
\hline Acute rejection grade, $\mathrm{n}(\%)$ & & & & .32 \\
\hline A0 & $42(48.8)$ & $18(60.0)$ & $24(42.9)$ & \\
\hline A1 & $22(38.4)$ & $9(30.0)$ & $24(42.9)$ & \\
\hline $\mathrm{A} 2 / \mathrm{B} 1 \mathrm{R}$ & $11(12.8)$ & $3(10.0)$ & $8(14.3)$ & \\
\hline Acute rejections before fundoplication, $\mathrm{n}(\%)$ & & & & .35 \\
\hline 0 & $65(75.6)$ & $26(86.7)$ & $39(69.6)$ & \\
\hline 1 or more & $21(24.4)$ & $4(13.3)$ & $17(30.4)$ & \\
\hline Acute rejections after fundoplication, $\mathrm{n}(\%)$ & & & & .10 \\
\hline 0 & $61(70.9)$ & $22(73.3)$ & $39(69.6)$ & \\
\hline 1 or more & $25(29.1)$ & $8(26.7)$ & $17(30.4)$ & \\
\hline Total number of acute rejections, $\mathrm{n}(\%)$ & & & & .46 \\
\hline 0 & $42(48.8)$ & $18(60.0)$ & $24(42.9)$ & \\
\hline 1 or more & $44(51.2)$ & $12(40.0)$ & $32(57.1)$ & \\
\hline Median survival, y & $3.5(2.4-4.7)$ & $3.1(2.4-4.0)$ & $3.9(2.4-4.8)$ & .20 \\
\hline BOS before fundoplication, $\mathrm{n}(\%) \dagger$ & $16 / 84(19.1)$ & $5 / 30(16.7)$ & $11 / 54(20.4)$ & .77 \\
\hline Alive at $1 \mathrm{y}, \mathrm{n}(\%)$ & $78(90.7)$ & $27(90.0)$ & $51(91.1)$ & 1.0 \\
\hline Alive at $3 \mathrm{y}, \mathrm{n}(\%)$ & $54 / 82(65.8)$ & $17 / 26(65.4)$ & $37 / 56(66.1)$ & .95 \\
\hline Alive at $5 \mathrm{y}, \mathrm{n}(\%)$ & $16 / 43(37.2)$ & $4 / 12(33.3)$ & $12 / 31(38.7)$ & 1.0 \\
\hline
\end{tabular}

All values expressed as median (interquartile range), unless indicated otherwise. $L O S$, Length of stay; BOS, bronchiolitis obliterans syndrome. *Calculated using Wilcoxon rank sum for continuous variables and Fisher exact for categorical variables. † $†$ Data missing for 2 patients. 
TABLE 3. Pretransplantation 24-hour pH study

\begin{tabular}{|c|c|c|c|c|}
\hline Variable & Overall $(\mathbf{n}=86)$ & Early fundoplication $(n=30)$ & Late fundoplication $(n=56)$ & $\boldsymbol{P}^{*}$ \\
\hline Median DeMeester score & $32.2(9.6-43.5)$ & $31.7(15.5-48.5)$ & $19.3(5.1-40.3)$ & .10 \\
\hline Median proximal channel total time $\mathrm{pH}<4$, min & $4(0.40-17.0)$ & $4.1(0.30-17)$ & $2.8(0.90-20.0)$ & .80 \\
\hline Median proximal channel upright time $\mathrm{pH}<4$, min & $2.0(0.30-12)$ & $3.5(0.30-11.1)$ & $2.0(0.10-15)$ & .87 \\
\hline Median proximal channel supine time $\mathrm{pH}<4$, min & $0.0(0.0-2.0)$ & $0.0(0.0-3.1)$ & $0.0(0.0-1.0)$ & .55 \\
\hline Median distal channel total time $\mathrm{pH}<4$, min & $70.9(16.0-136.0)$ & $99.5(41.0-147.7)$ & $58.6(12.9-125.6)$ & .21 \\
\hline Median distal channel upright time $\mathrm{pH}<4$, min & $37(10.3-109.0)$ & $52.8(20.8-101.7)$ & $31.5(5.1-109.9)$ & .21 \\
\hline Median distal channel supine time $\mathrm{pH}<4$, min & $7.0(1.0-41.0)$ & $9.2(1.0-43.6)$ & $3.0(0.65-31)$ & .41 \\
\hline Symptoms, n (\%) & & & & .74 \\
\hline Heartburn & $29(47.4)$ & $11(64.7)$ & $18(69.2)$ & \\
\hline Regurgitation & $1(2.3)$ & $1(5.9)$ & $0(0.0)$ & \\
\hline Chest & $1(2.3)$ & $0(0.0)$ & $1(3.9)$ & \\
\hline Cough & $12(27.9)$ & $5(29.4)$ & $7(26.9)$ & \\
\hline Median SAP symptom total (proximal), min & $0.0(0.0-8.2)$ & $0.0(0.0-32.0)$ & $0.0(0.0-6.6)$ & .50 \\
\hline Median SAP symptom total (distal), min & $0.0(0.0-94.0)$ & $21.3(0.0-99.5)$ & $0.0(0.0-64.0)$ & .08 \\
\hline
\end{tabular}

All values expressed as median (interquartile range), unless indicated otherwise. SAP, Symptom association probability. ${ }^{*}$ Calculated using Wilcoxon rank sum for continuous variables and Fisher exact for categorical variables.

late group. No pH studies were performed postfundoplication in either patient group.

\section{Disease Subgroups}

A greater proportion of patients who underwent fundoplication post-transplantation had obstructive lung disease as the underlying pulmonary diagnosis (53 of 86 ;
$61.6 \%$; Table 5). In a comparison of patients with obstructive and restrictive disease who underwent fundoplication for reflux, we found that patients with restrictive lung disease were more often men with higher LAS. Patients with restrictive lung disease had higher DeMeester scores and longer distal esophageal acid exposure times pretransplantation. However, DeMeester

TABLE 4. Prefundoplication metrics

\begin{tabular}{|c|c|c|c|c|}
\hline Variable & $\begin{array}{c}\text { Overall } \\
(\mathbf{N}=86)\end{array}$ & Early fundoplication $(\mathbf{n}=\mathbf{3 0})$ & Late fundoplication $(\mathrm{n}=56)$ & $P^{*}$ \\
\hline Median DeMeester score & $48.2(30.5-68.6)$ & $46.8(30.5-54.5)$ & $49.7(30.0-73.5)$ & .37 \\
\hline Median proximal channel total time $\mathrm{pH}<4$, min & $7.0(0.5-21.2)$ & $8.4(3.0-19.0)$ & $6.0(0.2-25.0)$ & .91 \\
\hline Median proximal channel upright time $\mathrm{pH}<4$, min & $3.0(0.1-11.9)$ & $5.1(1.8-8.9)$ & $1.6(0.1-14.3)$ & .54 \\
\hline Median proximal channel supine time $\mathrm{pH}<4$, min & $0.0(0.0-11.0)$ & $0.25(0.0-12.9)$ & $0.0(0.0-11.0)$ & .84 \\
\hline Median distal channel total time $\mathrm{pH}<4$, min & $147.0(87.5-215.6)$ & $144.9(87.5-173.9)$ & $147(86.0-244.8)$ & .61 \\
\hline Median distal channel upright time $\mathrm{pH}<4$, min & $66.4(34.8-132.8)$ & $55.5(26.8-132.8)$ & $77.6(36.0-134.0)$ & .64 \\
\hline Median distal channel supine time $\mathrm{pH}<4$, min & $54.2(12.8-97.6)$ & $37.9(24.0-73.3)$ & $58(7.2-106.0)$ & .53 \\
\hline Median SAP symptom total proximal & $0.0(0.0-79.9)$ & $0.0(0.0-96.0)$ & $0.0(0.0-11.9)$ & .54 \\
\hline Median SAP symptom total distal & $0.0(0.0-95.0)$ & $1.7(0.0-99.4)$ & $0(0.0-95.0)$ & .55 \\
\hline Median LESP, mm Hg & $23.4(12.5-30.4)$ & $25.5(15.7-31.3)$ & $22.1(11.8-28.5)$ & .32 \\
\hline Median total LES, $\mathrm{cm}$ & $3.4(3.1-3.7)$ & $3.3(2.9-3.6)$ & $3.5(3.2-3.9)$ & .02 \\
\hline Median abdominal LES, cm & $1.1(0.6-2.4)$ & $1.2(0.7-2.6)$ & $1.1(0.5-2.1)$ & .76 \\
\hline $\begin{array}{l}\text { Hiatal hernia size, n (\%) } \\
\text { Small } \\
\text { Large }\end{array}$ & $\begin{array}{c}40(47.6) \\
5(5.9)\end{array}$ & $\begin{array}{c}12(40.0) \\
2(6.7)\end{array}$ & $\begin{array}{c}28(51.9) \\
3(5.6)\end{array}$ & .58 \\
\hline EGD/Barrett pathology, n (\%) & $19(22.6)$ & $7(23.3)$ & $12(22.2)$ & .90 \\
\hline EGD evidence of esophagitis, $n(\%)$ & $45(53.6)$ & $12(40.0)$ & $33(61.1)$ & .06 \\
\hline
\end{tabular}

All values expressed as median (interquartile range), unless indicated otherwise. SAP, Symptom association probability; LESP, lower esophageal sphincter resting pressure; $L E S$, lower esophageal sphincter; $E G D$, esophagogastroduodenoscopy. *Calculated using Wilcoxon rank sum for continuous variables and Fisher exact for categorical variables. 
TABLE 5. Comparison of fundoplication patients according to major disease groups

\begin{tabular}{|c|c|c|c|}
\hline Variable & Obstructive lung disease $(n=53)$ & Restrictive lung disease $(n=23)$ & $P^{*}$ \\
\hline Median age at transplantation, y & $63(56-66)$ & $63(57-67)$ & .75 \\
\hline Median LAS & $32.7(31.9-34.1)$ & $41.6(37.6-55.4)$ & $<.001$ \\
\hline Male sex, $\mathrm{n}(\%)$ & $26(49.1)$ & $16(69.6)$ & .13 \\
\hline \multicolumn{4}{|l|}{ Pretransplantation $\mathrm{pH}$ study } \\
\hline Median DeMeester score & $15.5(4.6-34.1)$ & $41.8(26.9-56.3)$ & .001 \\
\hline Median proximal channel total time $\mathrm{pH}<4$, min & $2(0.8-21.6)$ & $4.5(0.3-10.0)$ & .68 \\
\hline Median distal channel total time $\mathrm{pH}<4$, min & $49.4(10.5-96.1)$ & $125.9(96.9-189.0)$ & $<.001$ \\
\hline Median time between lung transplant and hernia repair, mo & $11.0(6.1-15.3)$ & $5.7(2.4-16.1)$ & .10 \\
\hline \multicolumn{4}{|l|}{ Prefundoplication $\mathrm{pH}$ study $\dagger$} \\
\hline Median DeMeester score & $48(30.0-66.0)$ & $48.2(32.5-74.5)$ & .67 \\
\hline Median proximal channel total time $\mathrm{pH}<4$, min & $6(0.5-21.2)$ & $7.0(0.0-41.0)$ & .83 \\
\hline Median distal channel total time $\mathrm{pH}<4$, min & $139.5(86.0-215.6)$ & $164.1(96.9-244.8)$ & .59 \\
\hline Median total LES length, $\mathrm{cm}$ & $3.5(3.1-3.8)$ & $3.2(2.9-3.6)$ & .14 \\
\hline Median LESP, mm Hg & $23.0(10.4-31.3)$ & $19.6(15.3-31.4)$ & .62 \\
\hline Total number of acute rejection, $\mathrm{n}(\%)$ & & & .09 \\
\hline 0 & $29(54.7)$ & $9(39.1)$ & \\
\hline 1 or more & $24(45.3)$ & $14(60.9)$ & \\
\hline
\end{tabular}

All values expressed as median (interquartile range), unless indicated otherwise. $L A S$, Lung allocation score; $L E S$, lower esophageal sphincter; $L E S P$, lower esophageal sphincter resting pressure. *Calculated using Wilcoxon rank sum for continuous variables and Fisher exact for categorical variables. $\dagger$ Data missing for 2 patients.

score and proximal acid exposure times recorded prefundoplication were comparable between disease groups. Patients with restrictive lung disease had fundoplication earlier in their post-transplantation course (median, 5.7 months) compared with patients with obstructive lung disease (median, 11 months).

\section{Acute Rejection}

We calculated the number and severity of acute rejection episodes in total, as well as before and after fundoplication in both groups (Table 2). Although the late fundoplication group had a higher incidence of 1 or more episodes of acute rejection in total, this was not significant. The 2 groups were also comparable in terms of incidence of acute rejection after fundoplication, and in severity of acute rejection episodes.

\section{$\mathrm{FEV}_{1}$ and BOS}

The 2 groups differed in rate of lung function decline (Figure 1). The $\mathrm{FEV}_{1} \%$ increased by $2.5 \%(P=.22)$ over time in the early group compared with a decrease of $5.7 \%$ in the late group $(P<.001)$. The 5 -year percent predicted $\mathrm{FEV}_{1}$ was lower in the late group by $40.7 \%(P=.019)$. The adjusted linear mixed model showed that late fundoplication resulted in lower $\mathrm{FEV}_{1} \%$ than early fundoplication (Table 6). After stratification of fundoplication study group, the subgroup analyses showed a statistically significant decrease in $\mathrm{FEV}_{1} \%$ over time in both groups.

We further ascertained interactions via the linear mixed model between patient demographic and clinical characteristics with timing of fundoplication. Patients older than 60 years of age, LAS $>40$, obstructive end-stage lung disease, DeMeester score $>20$, and fundoplication length of stay $>2$ days were found to be effect modifiers with respect to the association between fundoplication timing and $\mathrm{FEV}_{1}$ decline over time (not shown).

In total, $19 \%$ of patients ( $16.7 \%$ early; $20.4 \%$ late $)$ met criteria for BOS grade 0-p or higher prefundoplication. ${ }^{1}$ Pulmonary function data were available for 83 of 86 patients for interpretation of freedom from BOS. Subgroup analysis showed comparable freedom from BOS in the early and late groups $(\log$-rank $P=.50$; Figure E1).

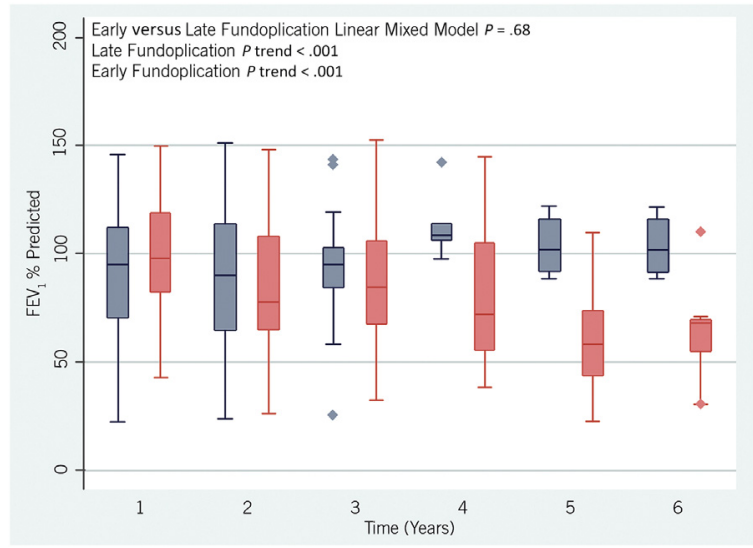

FIGURE 1. Linear mixed model showing differences in rate of decline in percent predicted $\mathrm{FEV}_{1}$ over time according to fundoplication group after transplantation. $F E V_{l}$, Forced expiratory volume in 1 second. 
TABLE 6. Comparison of FEV $_{1}$ decline between study groups after adjusting for confounding variables

\begin{tabular}{|c|c|c|c|c|c|c|}
\hline Study group & $\begin{array}{c}\text { Overall } \\
\text { Coefficient }(95 \% \text { CI }) \\
\end{array}$ & $P^{*}$ & $\frac{\text { Early fundoplication only }}{\text { Coefficient }(95 \% \text { CI })}$ & $\boldsymbol{P} \dagger$ & $\frac{\text { Late fundoplication only }}{\text { Coefficient }(95 \% \mathrm{CI})}$ & $\boldsymbol{P} \dagger$ \\
\hline Early fundoplication & Reference & & Reference & & Reference & \\
\hline Late fundoplication & $-3.64(-25.1$ to 5.80$)$ & .22 & N/A & & N/A & \\
\hline Time & $-4.67(-6.22$ to -3.12$)$ & $<.001$ & $-5.07(-7.29$ to -2.85$)$ & $<.001$ & $-4.63(-6.64$ to -2.63$)$ & $<.001$ \\
\hline
\end{tabular}

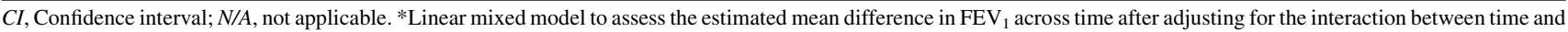
fundoplication status, age, sex, LAS, BMI at surgery, UNOS lung diagnosis, Karnofsky score, serum creatinine, interval between lung transplantation and fundoplication, DeMeester score, SAP symptom score, LES length, esophagitis, fundoplication LOS, number of rejections, time between last PFT and transplantation. $\dagger$ Linear mixed model to assess the estimated mean difference in $\mathrm{FEV}_{1}$ across time after adjusting for age, sex, LAS, BMI at surgery, UNOS lung diagnosis, Karnofsky score, serum creatinine, interval between lung transplantation and fundoplication, DeMeester score, SAP symptom score, LES, esophagitis, fundoplication LOS, number of rejections, time between last PFT and transplantation.

\section{Survival}

Survival was comparable in both fundoplication groups (log rank $P=.63$ ). One-year, 3-year, and 5-year survival rates in the early group were $90 \%, 70 \%$, and $70 \%$; in the late group, these rates were $91 \%, 66 \%$, and $66 \%$. Furthermore, compared with lung transplantation patients with normal $\mathrm{pH}$ studies and GERD patients without fundoplication, actuarial survival was not worse in either fundoplication group (log rank $P=.63)$.

\section{DISCUSSION}

Gastroesophageal reflux is prevalent in patients with end-stage lung disease awaiting lung transplantation ${ }^{5,12,13}$ and in patients who have undergone lung transplantation. ${ }^{13,14}$ Some have reported worsening of GERD post-transplantation. ${ }^{13-15}$ The reported rates of abnormal proximal acid exposure post-transplantation vary widely, but are generally lower than those seen in lung transplantation candidates. In our study, the prevalence of posttransplantation GERD was high (59\%). Fundoplication was performed for 1 of 2 reasons: symptomatic reflux corroborated on $\mathrm{pH}$ monitoring, or asymptomatic reflux at surveillance $\mathrm{pH}$ monitoring post-transplantation. Our rates of fundoplication post-transplantation were also higher $(34.5 \%)$ compared with rates described in the published literature, which range from $11 \%$ to $20 \%{ }^{16,17}$ These differences could be attributed to variation in institutional policies on the timing of fundoplication (ie, pretransplantation or post-transplantation). Furthermore, most institutions reserve $\mathrm{pH}$ testing for lung transplantation patients with symptomatic reflux or suspicion of aspiration-induced allograft injury. Hartwig et al ${ }^{18}$ reported rates of post-transplantation fundoplication as high as 53\% (including only patients who had $\mathrm{pH}$ testing pretransplantation). The high rates of fundoplication $(34.5 \%)$ in our lung transplantation population can be attributed to deferring the fundoplication to the posttransplantation period in patients with abnormal $\mathrm{pH}$ studies pretransplantation.

We also routinely refer all lung transplantation patients to an esophageal clinic post-transplantation and, if warranted, repeat a complete GERD evaluation (ie, endoscopy, 24-hour $\mathrm{pH}$ monitoring) 3 months after transplantation, regardless of whether GERD was evident during pretransplantation evaluation. All patients who underwent fundoplication had abnormal distal esophageal acid exposure times. Proximal acid exposure varied widely; fundoplication was offered in cases of abnormal distal acid exposure or abnormal DeMeester score $(>14.72)$ with or without evidence of proximal acid exposure on 24-hour $\mathrm{pH}$ monitoring.

Recently, some researchers have debated the reliability of proximal esophageal acid exposure as a surrogate for predicting aspiration in lung transplantation patients. Presence of $\operatorname{pepsin}^{19,20}$ and bile acids ${ }^{5,19,21}$ in bronchoalveolar lavage fluid have been shown to be more accurate predictors of gastroesophageal and gastroduodenal reflux, respectively, in these patients. However, use of these biomarkers remains limited to select centers, and $\mathrm{pH}$ studies in combination with endoscopy act as a widely used surrogate in cases of clinically suspected GERD-related aspiration. The presence of GERD in a patient undergoing lung transplantation is concerning for 2 main reasons: risk of aspiration-related allograft injury (ultimately contributing to allograft rejection), and the morbidity associated with fundoplication post-transplantation, which remains the only effective treatment for preventing reflux-related aspiration in this patient population. ${ }^{19}$

Although an association between reflux and lung transplantation is clear, controversy remains as to its role in the pathogenesis of allograft injury and CLAD. Some have reported stabilization of,${ }^{16}$ and sometimes, even improvement in lung function ${ }^{17}$ measured according to $\mathrm{FEV}_{1}$ after surgical correction of reflux posttransplantation. $\mathrm{FEV}_{1}$ decline is often used as a surrogate for BOS, which manifests pathologically as obliterative bronchiolitis. BOS is a common phenotype of CLAD in lung transplantation. ${ }^{22}$ Cantu et $\mathrm{al}^{8}$ showed that early fundoplication (within 90 days) was associated with a greater freedom from BOS. Fisichella et $\mathrm{al}^{7}$ showed that patients with any detectable pepsin in bronchoalveolar lavage fluid had quicker progression to BOS 
and more episodes of acute rejection, although they did not find a significant difference in time to BOS on the basis of treatment by early ( $<6$ months) or late antireflux surgery.

Lo et al, ${ }^{9}$ in their retrospective analysis of 48 patients, reported that patients who underwent late ( $>6$ months) antireflux surgery had significantly higher rates of early allograft injury (ie, acute rejection or lymphocytic bronchiolitis) compared with patients in their early fundoplication group. Results from our large singlecenter experience of 86 patients show that early surgical intervention before the onset of BOS $(<6$ months post-transplantation) in patients with a positive 24-hour $\mathrm{pH}$ monitoring study is associated with slower decline in lung function over the long term. However, we did not find any significant differences in rates of freedom from BOS and severity and number of acute rejections on the basis of the time of fundoplication after transplantation. This might be because of limitations in our study design, the multifactorial pathogenesis of BOS, and the presence of confounding factors. Despite this, our study clearly shows the positive effects of early surgical correction of GERD on long-term lung function posttransplantation.

Although most transplant centers now screen for preexisting GERD at the time of lung transplantation evaluation, the diagnosis and management of GERD in lung transplantation patients remain widely variable among transplant centers. No established guidelines for GERD surveillance exist for transplant recipients. In general, indications for surgical intervention for GERD after lung transplantation include evidence of symptomatic reflux, severe reflux as documented on $\mathrm{pH}$-monitoring or impedance study and/or endoscopy, bronchoscopic evidence of aspiration, and unexplained decline in pulmonary function. Patients with severe symptomatic reflux usually present early post-transplantation, necessitating surgical intervention. However, there remains a fraction of patients with proximal reflux and silent aspiration who undergo surgery only after a decline in lung function. It is the latter subgroup of patients that might benefit from routine, continued GERD surveillance post-transplantation. Furthermore, on the basis of recent data documenting improved pulmonary inflammatory milieu after surgical correction of GERD, ${ }^{6,15}$ and several single-center experiences showing an improvement in lung function from early fundoplication, a strong argument can be made for initiation of routine GERD surveillance early in the post-transplantation period (ie, within 3 months of transplantation).

Reported rates of mortality related to antireflux surgery have been historically low $(1.4 \%){ }^{23}$ Kilic et al, ${ }^{23}$ in their review of the nationwide inpatient sample, showed that fundoplication in lung transplant recipients is associated with longer length of stay and higher costs than in nontransplantation patients. However, previous lung transplantation was not an independent risk factor for in-hospital mortality postfundoplication. Although 5 of 86 patients in our study required revision surgery for failed fundoplication, we had no fundoplication-related mortality. Delayed gastric emptying requiring endoscopic dilation or pyloric injection of botulinum toxin occurred in 5 of 86 patients. There was no increased incidence of medical or wrap-related complications postfundoplication in our transplantation population. In light of our findings, and of others who have reported improved quality of life postfundoplication $^{24}$ with low morbidity, fundoplication appears to be a safe and effective treatment for GERD after transplantation.

Many authors have reported an association between underlying pulmonary diagnosis and incidence of GERD and esophageal motility disorders. ${ }^{12,25,26}$ In our study, most post-transplantation fundoplications were performed in patients who underwent transplantation for obstructive lung disease. Restrictive lung disease patients who required posttransplantation fundoplication had higher pretransplantation DeMeester scores compared with patients with obstructive lung disease. This is likely because patients with restrictive lung disease awaiting lung transplantation often have severe pretransplantation GERD and poor esophageal motility. Poor esophageal motility can exacerbate reflux because of inadequate acid clearance from the esophagus, which explains the differences in pretransplantation $\mathrm{pH}$ studies in the 2 disease groups. It is also likely that patients with restrictive disease had a lower threshold for post-transplantation fundoplication, as evidenced by the shorter time between transplantation and fundoplication. This is likely because of positive $\mathrm{pH}$ studies at the time of transplantation evaluation, continued symptoms, and/or concern for aspiration-related allograft injury because of concomitant esophageal dysmotility. We are currently undertaking further studies to objectively assess rates of esophageal motor disorders and their association with GERD in our post-transplantation population.

This study drives home the importance of early and routine referrals of lung transplant recipients to esophageal clinics. Our study has validated the importance of early surgical intervention for GERD and the ability of fundoplication to slow the pulmonary function decline post-transplantation. Although BOS is multifactorial, our data do indicate a slower decline in $\mathrm{FEV}_{1}$ after early fundoplication. Despite intervention to prevent aspiration-related allograft injury, we have seen neither improvement in lung function after fundoplication nor a significant difference in the onset of BOS, contrary to observations made by Davis et al. ${ }^{17}$ A potential explanation for this would be our small sample size and the multifactorial etiology of BOS. Another potential explanation would be that even a short median intervention time of 4.6 months post-transplantation (as seen in our early fundoplication 
group) might be too late in the continuum of irreversible events associated with allograft injury that ultimately result in BOS. Additionally, this study constitutes one of the largest modern single-center experiences with antireflux surgery in the lung transplantation population to date (after Hartwig et al, ${ }^{18}$ who described 157 patients over 8.5 years). We also report specific characteristics of patients (ie, lung transplant recipients older than 60 years, LAS $>40$, obstructive lung disease, and DeMeester score $>20$ ) who stand to benefit the most from early fundoplication posttransplantation. We believe our current practice of esophageal surveillance beginning 3 months post-transplantation is a protocol worth adopting, because of the high prevalence of GERD and its implications on allograft function after lung transplantation. In a recent study, Ehrsam et $\mathrm{al}^{27}$ reported GERD as an independent predictor of mortality in lung transplant recipients aged 60 years or older. This also raises the question of whether patients should be considered for fundoplication earlier than 6 months, especially in older recipients.

This study is limited by its retrospective nature and lack of a control arm. The biggest confounder in this study was the presence of unaccounted variables that could affect decline in lung function and freedom from BOS differently in the 2 patient groups. Another is the delay in fundoplication because of unforeseen complications in some patients in the late fundoplication group. As shown by Chan et al, ${ }^{28}$ one might argue that some patients in the late fundoplication group were doomed to have worse allograft outcomes as a result of the "ripple effect" from immediate post-transplantation complications unrelated to GERD. Furthermore, some antireflux procedures offered to patients in the late fundoplication group might be construed as "too little, too late" in the continuum of BOS development. We do not have objective studies that have yet investigated bronchoalveolar aspiration markers (eg, pepsin, bile acid) or persistent reflux (24-hour $\mathrm{pH}$ study) in patients postfundoplication. Finally, because of the limited number of patients in our study, our 3- and 5 -year survival numbers might be somewhat skewed.

\section{CONCLUSIONS}

GERD appears to become more severe after lung transplantation, but early fundoplication might slow the rate of lung function decline after transplantation. In this study, patients who underwent early fundoplication had a higher $\mathrm{FEV}_{1} 5$ years after transplantation. Early fundoplication might protect against GERD-induced lung damage in transplant recipients with pretransplantation GERD.

\section{Conflict of Interest Statement}

Authors have nothing to disclose with regard to commercial support.

\section{References}

1. Meyer KC, Raghu G, Verleden GM, Corris PA, Aurora P, Wilson KC, et al. An international ISHLT/ATS/ERS clinical practice guideline: diagnosis and management of bronchiolitis obliterans syndrome. Eur Respir J. 2014;44:1479-503.

2. Belperio JA, Weigt SS, Fishbein MC, Lynch JP III. Chronic lung allograft rejection: mechanisms and therapy. Proc Am Thorac Soc. 2009; $6: 108-21$

3. Weigt SS, Wallace WD, Derhovanessian A, Saggar R, Saggar R, Lynch JP, et al. Chronic allograft rejection: epidemiology, diagnosis, pathogenesis, and treatment. Semin Respir Crit Care Med. 2010;31:189-207.

4. Bobadilla JL, Jankowska-Gan E, Xu Q, Haynes LD, Munoz del Rio A, Meyer K, et al. Reflux-induced collagen type $\mathrm{V}$ sensitization: potential mediator of bronchiolitis obliterans syndrome. Chest. 2010;138:363-70.

5. D'Ovidio F, Singer LG, Hadjiliadis D, Pierre A, Waddell TK, de Perrot M, et al. Prevalence of gastroesophageal reflux in end-stage lung disease candidates for lung transplant. Ann Thorac Surg. 2005;80:1254-60.

6. Fisichella PM, Davis CS, Lowery E, Pittman M, Gagermeier J, Love RB, et al. Pulmonary immune changes early after laparoscopic antireflux surgery in lung transplant patients with gastroesophageal reflux disease. J Surg Res. 2012;177:e65-73.

7. Fisichella PM, Davis CS, Lundberg PW, Lowery E, Burnham EL, Alex CG, et al. The protective role of laparoscopic antireflux surgery against aspiration of pepsin after lung transplantation. Surgery. 2011;150:598-606.

8. Cantu E III, Appel JZ III, Hartwig MG, Woreta H, Green C, Messier R, et al. J. Maxwell Chamberlain Memorial Paper. Early fundoplication prevents chronic allograft dysfunction in patients with gastroesophageal reflux disease. Ann Thorac Surg. 2004;78:1142-51; discussion 51.

9. Lo WK, Goldberg HJ, Wee J, Fisichella PM, Chan WW. Both pre-transplant and early post-transplant antireflux surgery prevent development of early allograft injury after lung transplantation. J Gastrointest Surg. 2016;20:111-8; discussion 8.

10. Richter JE, Pandolfino JE, Vela MF, Kahrilas PJ, Lacy BE, Ganz R, et al. Utilization of wireless $\mathrm{pH}$ monitoring technologies: a summary of the proceedings from the Esophageal Diagnostic Working Group. Dis Esophagus. 2013;26: 755-65.

11. Stewart S, Fishbein MC, Snell GI, Berry GJ, Boehler A, Burke MM, et al. Revision of the 1996 working formulation for the standardization of nomenclature in the diagnosis of lung rejection. J Heart Lung Transplant. 2007;26:1229-42.

12. Basseri B, Conklin JL, Pimentel M, Tabrizi R, Phillips EH, Simsir SA, et al. Esophageal motor dysfunction and gastroesophageal reflux are prevalent in lung transplant candidates. Ann Thorac Surg. 2010;90:1630-6.

13. Young LR, Hadjiliadis D, Davis RD, Palmer SM. Lung transplantation exacerbates gastroesophageal reflux disease. Chest. 2003;124:1689-93.

14. Hadjiliadis D, Duane Davis R, Steele MP, Messier RH, Lau CL, Eubanks SS, et al. Gastroesophageal reflux disease in lung transplant recipients. Clin Transplant. 2003; 17:363-8.

15. Fisichella PM, Davis CS, Gagermeier J, Dilling D, Alex CG, Dorfmeister JA, et al. Laparoscopic antireflux surgery for gastroesophageal reflux disease after lung transplantation. J Surg Res. 2011;170:e279-86.

16. Abbassi-Ghadi N, Kumar S, Cheung B, McDermott A, Knaggs A, Zacharakis E, et al. Anti-reflux surgery for lung transplant recipients in the presence of impedance-detected duodenogastroesophageal reflux and bronchiolitis obliterans syndrome: a study of efficacy and safety. J Heart Lung Transplant. 2013;32:588-95.

17. Davis RD Jr, Lau CL, Eubanks S, Messier RH, Hadjiliadis D, Steele MP, et al. Improved lung allograft function after fundoplication in patients with gastroesophageal reflux disease undergoing lung transplantation. $J$ Thorac Cardiovasc Surg. 2003;125:533-42.

18. Hartwig MG, Anderson DJ, Onaitis MW, Reddy S, Snyder LD, Lin SS, et al. Fundoplication after lung transplantation prevents the allograft dysfunction associated with reflux. Ann Thorac Surg. 2011;92:462-8; discussion 8-9.

19. Blondeau K, Mertens V, Vanaudenaerde BA, Verleden GM, Van Raemdonck DE, Sifrim D, et al. Gastro-oesophageal reflux and gastric aspiration in lung transplant patients with or without chronic rejection. Eur Respir J. 2008;31:707-13.

20. Stovold R, Forrest IA, Corris PA, Murphy DM, Smith JA, Decalmer S, et al. Pepsin, a biomarker of gastric aspiration in lung allografts: a putative association with rejection. Am J Respir Crit Care Med. 2007;175:1298-303.

21. D’Ovidio F, Mura M, Ridsdale R, Takahashi H, Waddell TK, Hutcheon M, et al. The effect of reflux and bile acid aspiration on the lung allograft and its surfactant and innate immunity molecules SP-A and SP-D. Am J Transplant. 2006;6: 1930-8.

22. Verleden GM, Raghu G, Meyer KC, Glanville AR, Corris P. A new classification system for chronic lung allograft dysfunction. J Heart Lung Transplant. 2014;33: $127-33$. 
23. Kilic A, Shah AS, Merlo CA, Gourin CG, Lidor AO. Early outcomes of antireflux surgery for United States lung transplant recipients. Surg Endosc. 2013;27: 1754-60.

24. Robertson AG, Krishnan A, Ward C, Pearson JP, Small T, Corris PA, et al. Antireflux surgery in lung transplant recipients: outcomes and effects on quality of life. Eur Respir J. 2012;39:691-7.

25. el-Serag HB, Sonnenberg A. Comorbid occurrence of laryngeal or pulmonary disease with esophagitis in United States military veterans. Gastroenterology. 1997; 113:755-60

26. Seccombe J, Mirza F, Hachem R, Gyawali CP. Esophageal motor disease and reflux patterns in patients with advanced pulmonary disease undergoing lung transplant evaluation. Neurogastroenterol Motil. 2013;25:657-63.
27. Ehrsam JP, Benden C, Seifert B, Opitz I, Schneiter D, Weder W, et al. Lung transplantation in the elderly: influence of age, comorbidities, underlying disease, and extended criteria donor lungs. J Thorac Cardiovasc Surg. 2017; 154:2135-41.

28. Chan EG, Bianco V III, Richards T, Hayanga JW, Morrell M, Shigemura N, et al. The ripple effect of a complication in lung transplantation: evidence for increased long-term survival risk. J Thorac Cardiovasc Surg. 2016;151: 1171-9.

Key Words: fundoplication, gastroesophageal reflux, lung transplantation 


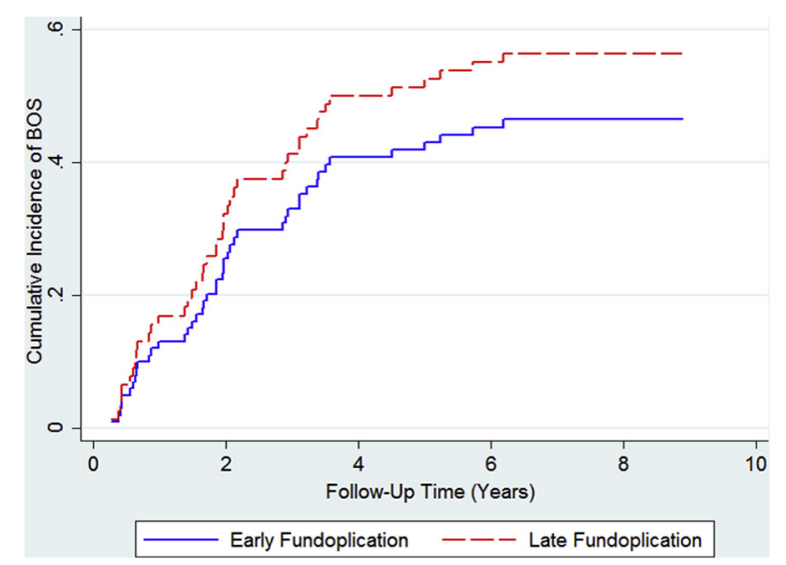

FIGURE E1. Cumulative incidence of BOS at follow-up, constructed using the competing risk extension of the Kaplan-Meier method where death is regarded as a competing risk. BOS, Bronchiolitis obliterans syndrome. 